Clye cintes. 


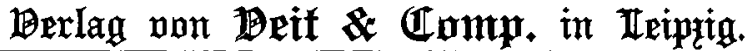 Des Ariftophanes Daerke. \\ überjegt bon

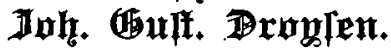 \\ Dritte $\mathfrak{X}$ uffage.
}

3wei Teile. gr. 8. geh. $12 \mathscr{H}$; in einem Bante gebundent 13 Ah 60 F.

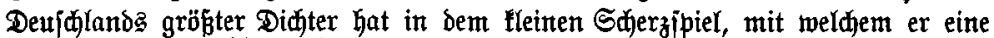

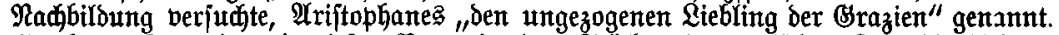
Boethe wußste, ein wie tiefer Born in ben Stüfen bes attijden Romöbiendidters

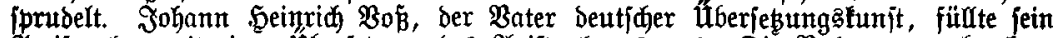
Greifenalter mit einer úberfebung bes YYriftophanes aus. Die Bahn war gebroden, immer bon neuem reizte bie Autgabe. Riemand aber hat ez beffer verftanden, den

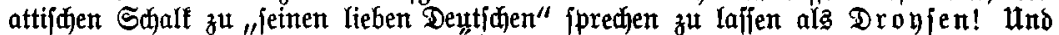
twenn jebt bie britte $\mathfrak{A}$ uflage jeiner úberfebung an unfereş Bolfes Thär um Einla bittet, fo zieft fie eit, wie ein guter Freumb unjerer Jugentseit und wie ber ernft= Geitere Senos bes Mannes.

\section{Geschichte der neueren Philosophie}

\author{
von Nikolaus von Kues bis zur Gegenwart. \\ I m G r ndriss dargestellt. \\ Von \\ Dr. A. Falckenberg, \\ Professor an der Universität Jena.

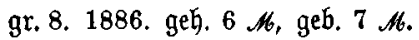

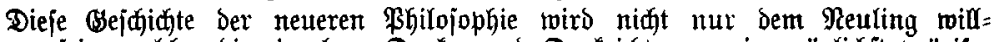
fommen jein, weldher bie einzelnen Denfer und Denfridgtungen in möglidjit präzijer Fajiung autbentija darafterifiert jeben möbte, jondern auth allen Bebildeten, weldhe

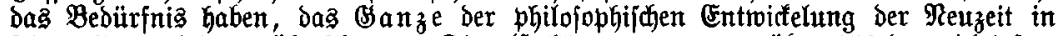

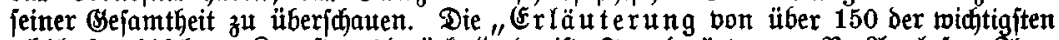

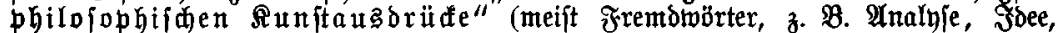

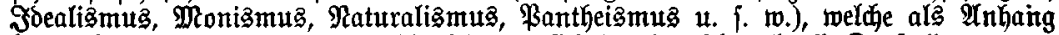

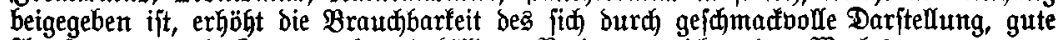

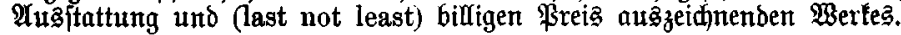

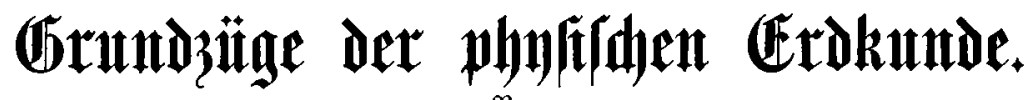 Bon Prof. Dr. Alexander Supan,}

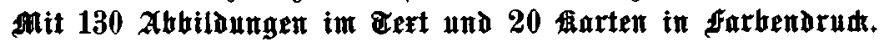

gr. 8. 1884. geh. 7 A6.

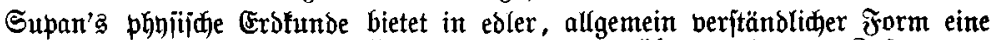

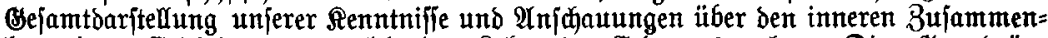

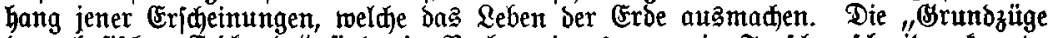

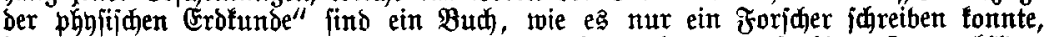

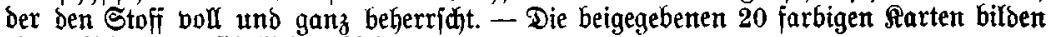
einen tleinen phyjifalipden $\mathfrak{A t l a}$. 


\title{
The Times
}

I2v. 31,725.

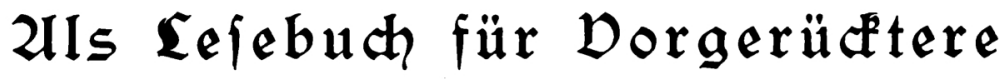

\author{
bearbeitet
}

pon

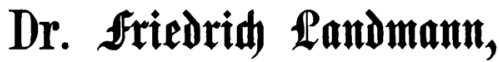

Sebrex ber englifめen Gprade an ber Offentliden Sanbelstebranftalt gu Beipaig.

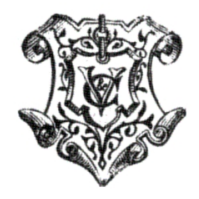

Teipził

$\mathfrak{B e r l a g} \mathfrak{v o n} \mathfrak{B e i t} \&$ Eomp.

1888.

London: Whusams \& Norqate, 14 Henrietta Street, Covent Garden;

D. NuTr, 270 Strand; TrüBner \& Co., 57 \& 59 Ludgate Hill. 
Drut von Megger \& $\$$ ittig in Seipzig. 